\title{
VENTAS EN MARTILLO POR ORDEN JUDICIAL Y SU IMPUGNACIÓN
}

\author{
Alberto Viada Lozano \\ Profesor de Derecho Comercial \\ Universidad Católica del Norte, Coquimbo
}

El principio general sustentado en el artículo 2.465 del Código Civil, de que "toda obligación personal da al acreedor el derecho de perseguir su ejecución sobre todos los bienes raíces o muebles del deudor, sean presentes o futuros, exceptuándose solamente los no embargables...", denominado comúnmente como "prenda general de los acreedores", requiere de ciertas distinciones para los efectos de este ensayo; especialmente, determinar si la obligación personal es de dar, hacer o no hacer, y, dentro de las obligaciones de dar, distinguir también si se trata de dar una especie o cuerpo cierto, un género, cosas fungibles 0 , más específicamente, dinero. Para delimitar este trabajo, nos centraremos en la ejecución de una obligación de dar una cantidad de dinero, sea que esa obligación emane directamente del acto o contrato o de una sentencia judicial que ordene dicho pago de dinero, provenga de una condena a indemnizar perjuicios, o se trate del valor de una especie debida que no exista en poder del deudor, o tenga cualquier otro origen.

La otra aclaración previa, además de que se trate de una obligación de dar una suma determinada de dinero, es que en el tema en estudio se persigue la ejecución de esa obligación personal sobre bienes muebles del deudor. En otras palabras, al ejercer este "derecho de prenda general", aplicando analógicamente el artículo 2.397 del Código Civil, el acreedor tendrá derecho a pedir que los bienes muebles del deudor moroso se vendan mediante pública subasta para que con su producido se le pague.

Se refiere a esta realización de bienes el Código de Procedimiento Civil, sea al tratar "de la ejecución de las resoluciones" en general, Título XIX del Libro I, o refiriéndose al "juicio ejecutivo en las obligaciones de dar", Título I del Libro III. En efecto, el artículo 235 de dicho Código dispone que: "Si no ha habido oposición al cumplimiento de la sentencia solicitado conforme al artículo 233 o ella ha sido desestimada por sentencia de primera o segunda instancia, se procederá a cumplirla, siempre que la ley no haya dispuesto otra forma especial, de acuerdo a las reglas siguientes: .... $3^{\text {a }} \mathrm{Si}$ la sentencia manda pagar una suma de dinero... se dispondrá previamente la realización de los bienes que estén garantizando el resultado de la acción conforme al Título $\mathrm{V}$ del Libro II". "Si no hay bienes que aseguren el resultado de la acción se procederá a embargar y enajenar bienes suficientes de la parte vencida de acuerdo con las reglas del procedimiento de apremio, sin necesidad de requerimiento...". Por su parte, el artículo 481 ordena: "Notificada que sea la sentencia remate, se procederá a la venta de los bienes embargados, de conformidad a los artículos siguientes", aclarando el artículo 
482: "Los bienes muebles embargados se venderán en martillo, siempre que sea posible, sin necesidad de tasación. La venta se hará por el martillero designado por el tribunal que corresponda".

Pues bien, la inquietud que quisiera plantear $y$, de ser posible, ayudar a esclarecer, tiene relación con los efectos recíprocos que las normas procesales y comunes pueden causar en esta venta tan especial que, por un parte, al ser contrato de compraventa, está regida por leyes de fondo, pero que, por ser consecuencia de un procedimiento judicial, está sometida a normas adjetivas, de entre las que más podrían afectarle serían las relativas a la nulidad procesal. Para ello será necesario precisar algunos conceptos:

Martillero.- Siguiendo la norma de interpretación legal contenida en el artículo 20 del Código Civil, ya que si el legislador ha definido expresamente una palabra para ciertas materias, se les dará en éstas su significado legal, recurriremos a la ley 18.118 , publicada en el Diario Oficial del 22 de mayo de 1982, sobre el ejercicio de la actividad de martillero público, en cuyo artículo $1^{\circ}$ aparece la siguiente definición: "Son martilleros las personas naturales o jurídicas inscritas en un registro, en conformidad a esta ley, para vender públicamente al mejor postor toda clase de bienes corporales muebles".

La misma ley señala en sus artículos $2^{\circ}$ a $5 \circ$ los requisitos e inhabilidades para poder ser inscrito en el registro y, por ende, ser martillero, tanto como persona natural como jurídica, y en artículos posteriores se establece que el Registro Nacional de Martilleros lo lleva la Subsecretaría de Economía, Fomento y Reconstrucción, estableciéndose sus facultades y obligaciones al efecto.

Para aclarar más el concepto de martillero, el artículo 17 de la misma ley dispone que: "Los martilleros servirán únicamente de intermediarios para las ventas en martillo y les estará prohibido:

a) Tomar parte en las licitaciones que se realicen por su intermedio, ya sea por sí o por interpósita persona;

b) Adquirir del licitador las especies en cuya subasta haya intervenido, $y$

c) Alterar el juego normal de las posturas y el precio natural de las subastas mediante maniobras de cualquier índole".

Para completar el concepto de martillero deberíamos además considerar que, conforme al artículo $3^{\circ}$ del Código Comercio: "Son actos de comercio, ya de parte de ambos contratantes, ya de parte de uno de ellos... $7^{\circ}$ Las empresas de depósito de mercaderías, provisiones o suministros, las agencias de negocios y los martillos". Y, como el artículo $7^{\circ} \mathrm{del}$ mismo Código dispone que: "Son comerciantes los que, teniendo capacidad para contratar, hacen del comercio su profesión habitual", podemos concluir que los martilleros tienen la calidad de comerciantes.

Por último, atendido que no pueden vender personalmente ni comprar para sí las especies a su cargo, sino que son meros "intermediarios" para las ventas en martillo, puede calificarse su actividad como la de comisionista para vender, por lo que las normas de los párrafos $2^{\circ}, 3^{\circ}$ y $5^{\circ}$ del Título I del Libro II del Código de Comercio pueden 


\section{Alberto Viada Lozano - Ventas en Martillo por orden judicial...}

aplicarse a su respecto en subsidio de la ley 18.118 , siempre que no sean contrarias a la especial naturaleza de este tipo de venta y comisión.

Podemos concluir, entonces, que en Chile el martillero es una persona natural o jurídica comerciante, comisionista para vender públicamente al mejor postor toda clase de bienes corporales muebles ajenos, autorizado para ello mediante su inscripción en el Registro Nacional de Martilleros, a cargo de la Subsecretaría de Economía, Fomento y Reconstrucción.

Ventas en martillo o remates.- Del texto de los artículos $1^{\circ}, 12^{\circ}, 13^{\circ}, 15^{\circ}, 17^{\circ} \mathrm{y}$ otros de la ley 18.118 , aparece evidente que para el legislador "venta en martillo" y "remate" son conceptos sinónimos, pero en ninguna parte los define, si bien de las disposiciones que los reglamentan podemos extraer sus principales características. Veamos:

En primer lugar, del mismo concepto de martillero contenido en el artículo $1^{\circ}$ de la ley, resulta evidente que se trata de una "venta"; que esta venta debe efectuarse "públicamente"; que el comprador será el "mejor postor", y que debe recaer sobre "bienes corporales muebles". Cabe agregar que las especies muebles objeto del remate deben pertenecer a un tercero ajeno al martillero, puesto que éste "servirá únicamente de intermediario para las ventas en martillo".

Hay un término o concepto muy ligado a la materia, incluso contemplado muchas veces como sinónimo de remate, pero del que quisiera aclarar la sutil diferencia. Me refiero a la "subasta". Dice el Diccionario de la Real Academia de la Lengua Española que esta palabra proviene del latín "sub-asta", bajo la lanza, porque la venta del botín de guerra se anunciaba con una lanza, lo que se hacía al mejor postor, pero agrega que la frase "sacar a pública subasta" significa "ofrecerla a quien haga proposiciones más ventajosas en las condiciones prefijadas". En cambio "remate" (de "rematar") significa, "Fin o cabo, extremidad o conclusión de una cosa"; "Postura o proposición que obtiene la preferencia y se hace eficaz logrando la adjudicación en subastas o almonedas para compraventas...". En consecuencia, el lícito juego de propuestas y contrapropuestas, en los términos de los artículos 97, 101 y 102 del Código de Comercio, para formar el consentimiento de la compraventa en martillo, es la "subasta", y el momento de la formación del consentimiento por la aceptación del precio y la determinación del comprador, el mejor postor, es el "remate" o "venta en martillo", (dícese así porque ordinariamente se da un martillazo para denotar que queda hecha o firme la venta". Dicc. Acepción $6^{a}$ de la palabra "martillo").

Entonces podríamos describir la venta en martillo o remate como un contrato de compraventa de cosas corporales muebles, en que el precio se conviene mediante pública subasta, el vendedor actúa por intermedio de un martillero y el comprador es el mejor postor.

Vínculo entre martillero y vendedor- Ya vimos que el artículo 17 de la Ley 18.118 dispone perentoriamente que "los martilleros servirán únicamente de intermediarios para las ventas en martillo...". Sin embargo, es el martillero el que acepta el 
precio final y la determinación del comprador, el mejor postor. En otras palabras, es el martillero quien presta el consentimiento para la celebración del contrato de compraventa y la posterior tradición o entrega de los bienes rematados. Pero no lo hace a nombre propio, sino del vendedor, en los términos señalados en el artículo 1.448 del Código Civil: "Lo que una persona ejecuta a nombre de otra, estando facultado por ella o por la ley para representarla, produce respecto del representado iguales efectos que si hubiese contratado él mismo".

Y el vínculo jurídico que faculta al martillero para representar al vendedor es una comisión para vender, reconocida en varias disposiciones de la ley 18.118 y su Reglamento, por ejemplo: "El vendedor tendrá derecho para impedir la repetición del remate...". (Art. 15 inc. final Ley); "La comisión del martillero y el plazo de presentación de la cuenta se fijarán de común acuerdo, entre éste y el comitente..."; "Con la presentación de la cuenta, el martillero pagará al comitente el saldo que resulte a su favor"; "El martillero moroso en la exhibición de la cuenta o entrega del saldo, perderá su comisión. Además, deberá pagar la suma que adeuda a su comitente con el interés...". (Art. 16 Ley); "El martillero deducirá de dichos dineros los gastos de avisos u otros que demande la subasta y su comisión...". (Art. 21 inc. final Ley); "Del producto del remate deducirá la comisión e impuestos...". (Art. 22 inc. $1^{\circ}$ Ley); "Un convenio entre el vendedor y el martillero deberá contener las condiciones del remate y los derechos y obligaciones de las partes en materia de gastos, comisiones, rendición de cuentas, garantías, y los efectos que produce el desistimiento...". (Art. $3^{2}$ Reglamento).

Pese a que naturalmente estamos frente a una comisión para vender, induce a dudas lo dispuesto en el artículo 25 de la ley, a saber: "El martillero recibirá las especies que se le entreguen para la subasta, en calidad de depositario, y deberá otorgar al comitente recibo detallado de las mismas". La verdad es que esta disposición no altera en absoluto la naturaleza de la comisión para vender, puesto que la misma norma denomina "comitente" a quien según ella debería llamarse "depositante". Y, siendo el martillo siempre un acto de comercio, este denominado depósito, accesorio al negocio principal de comisión para vender, debe regirse por las normas del Código de Comercio, especialmente las establecidas en el Título XIV de su Libro II, de las que transcribo las más atinentes: "Art. 807. El depósito mercantil se constituye en la misma forma que la comisión", y "Art. 808. Los derechos y obligaciones del depositante y depositario de mercaderías son los mismos que otorga e impone este Código a los comitentes y comisionistas".

El texto del artículo 25 de la ley 18.118, transcrito precedentemente, es una demostración de cómo el afán de impedir las irregularidades en el ejercicio de la actividad de los martilleros, que a la sazón se aprovechaban libremente para comerciar sus propias mercaderías, hace incurrir a los legisladores en contradicciones evidentes. En efecto, si por definición el martillero tiene la función de vender públicamente al mejor postor toda clase de bienes corporales muebles, sirviendo únicamente de intermediario para las ventas en martillo, resulta jurídicamente imposible que reciba las especies en calidad de depositario, puesto que es de la esencia del depósito que el depositario es 
obligado a la restitución de las mismas cosas individuales que se le han confiado, con todas sus accesiones y frutos (artículos 2.228 y 2.229 del Código Civil). Ni siquiera es mayor la responsabilidad civil del depositario que la del comisionista (ver artículos 2.222 del Código Civil y 246, 247, 248 y 249 del Código de Comercio). Y en cuanto a la responsabilidad penal, vemos que el artículo 470 № $1^{\circ}$ del Código Penal, sanciona a los que en perjuicio de otro se apropiaren o distrajeren cualquiera cosa mueble que hubieren recibido en depósito, comisión, etc., por lo que respondería el martillero en su calidad de comisionista, sin necesidad de atribuirle la calidad de depositario.

En resumen, a pesar del texto del artículo 25 de la Ley, resulta evidente que el contrato que los vincula y permite al martillero vender y efectuar la tradición de los bienes corporales muebles del vendedor es una comisión para vender, mandato comercial especial.

Remate judicial.- Ya vimos que el remate es una compraventa de cosas corporales muebles, en que el precio y la persona del comprador se determinan tras una subasta pública, y la persona del vendedor está representada por el martillero. Pues bien, en el remate judicial no se altera este concepto, sino que quien celebra el contrato de comisión para vender es el juez, como representante legal del vendedor. Ello se desprende de las siguientes disposiciones:

Artículos 481 y 482 del Código de Procedimiento Civil: "Notificada que sea la sentencia de remate, se procederá a la venta de los bienes embargados, de conformidad a los artículos siguiente". "Los bienes muebles embargados se venderán en martillo, siempre que sea posible, sin necesidad de tasación. La venta se hará por el martillero designado por el tribunal que corresponda".

Articulo 671, inciso tercero, del Código Civil: "En las ventas forzadas que se hacen por decreto judicial a petición de un acreedor, en pública subasta, la persona cuyo dominio se transfiere es el tradente, y el juez su representante legal".

Entonces tenemos que no existe ninguna diferencia en lo que es propiamente el remate o venta en martillo; sólo sucede que el contrato de comisión para vender, en vez de celebrarlo el martillero directamente con el dueño de los muebles, lo hace con el juez de la causa, en su calidad de representante legal del vendedor.

Y esto se demuestra en la propia ley 18.118 , en cuyo Título IV, al reglamentar "los remates judiciales", sólo se refiere al vínculo entre el martillero y el vendedor, comitente, en este caso representado legalmente por el juez. Veamos: el artículo 19 dispone en su inciso primero que "los remates judiciales de especies muebles serán realizados por el martillero que designe el juez de la causa", destinando los incisos siguientes a reglamentar la forma en que debe hacerse la designación y la prohibición para el martillero de eximirse una vez designado. El artículo 20 establece un registro de martilleros que cumplan los requisitos legales y reglamentarios, que debe mantener la Corte de Apelaciones, de entre cuyos inscritos deberá hacer la designación para cada caso el juez respectivo. El artículo 21, en su inciso primero, dispone que "los dineros que se obtengan como producto del remate serán puestos por el martillero a disposición del tribunal 
respectivo dentro de los cinco días hábiles siguientes al día del remate", destinando el inciso segundo a establecer las únicas retenciones que podría hacer el martillero ("gastos de avisos u otros que demande la subasta y su comisión, la que no podrá exceder del $1 \%$ del producto del remate" ). Por último, el artículo 22 establece la dependencia del martillero respecto de las órdenes de suspensión que emanen de resoluciones judiciales (siempre el comisionista está sometido a las instrucciones del comitente), y confiere una facultad especial para efectuar el remate si las especies permanecen en su poder por más de tres meses, contados desde la fecha de suspensión, "salvo resolución en contrario dictada por el juez de la causa", y, previas las deducciones facultadas por la ley, "el remanente del producto será consignado por el martillero en el juicio que originó la subasta dentro del plazo de cinco días, contados desde la fecha del remate".

No cabe ninguna duda, entonces, que los remates son todos iguales, variando sólo en el remate judicial el contrato de comisión para vender, en que la libre elección del comisionista está seriamente limitada; está prohibido el rechazo de la comisión por parte del martillero, y sus salarios están restringidos a un máximo del $1 \%$ del remate.

\section{LEGISLACIONES APLICABLES AL REMATE JUDICIAL}

Tenemos que distinguir, de acuerdo a lo expuesto precedentemente, el remate propiamente tal y la comisión para vender que origina el remate.

Legislación del remate.- Como ya dijimos, el remate es un contrato de compraventa de cosas corporales muebles, en la que el precio se conviene mediante subasta pública, el vendedor actúa por intermedio de un martillero y el comprador es el mejor postor.

Como consecuencia de ello, la legislación aplicable será principalmente la de la propia ley 18.118, (especialmente su Título II); su Reglamento, Decreto № 132 publicado en el Diario Oficial del 1ํ de junio de 1982, (especialmente su Título II); el Código de Comercio, (especialmente el Título I, párrafo 1. "De la constitución, forma y efectos de los contratos y obligaciones" y el Título II: "De la compraventa", ambos del Libro II) y el Código Civil (del Libro IV, principalmente los Títulos I, II, XII, XIII, XIV, XX y XXIII, éste último que trata especialmente "De la compraventa").

Legislación de la comisión para vender.- Es el contrato que origina el remate, sin él no habría venta en martillo, puesto que el martillero sólo puede actuar como intermediario, rematando los bienes corporales muebles que le encargue el comitente.

Obviamente que también en esto se aplican primordialmente las normas pertinentes existentes en la ley 18.118 (Títulos I y II, y Arts. 16, 17 y 25) y su Reglamento (Art. $3^{\circ}$ ), pero principalmente las normas de los párrafos $1,2,3$ y 5 del Título VI del Libro II del Código de Comercio y del Título XIX del Libro IV del Código Civil, todas ellas relativas al mandato, la comisión y la comisión para vender en especial.

Legislación adicional para los remates judiciales.- En relación a los remates dispuestos por los tribunales, sólo existen normas especiales relativas a la comisión para 
vender, como ya se dijo anteriormente, y, además, todas las normas procesales relativas a la tramitación del juicio, causa, pleito, gestión judicial, o cualquier tipo de actuación procesal en la que se ordenó el remate.

Estas normas procesales pueden afectar, en mi opinión, solamente a la comisión para vender, pero no podrían invalidar el remate mismo. Es lo que trataremos de dilucidar a continuación.

\section{ACCIONES RELACIONADAS CON EL REMATE JUDICIAL}

Como ya se dejó establecido precedentemente, el remate, judicial o no, es un contrato de compraventa en la que el vendedor actúa representado por el martillero y el precio y la persona del comprador se determinan mediante un libre juego de propuestas y contrapropuestas (ver Arts. 97, 101 y 102 del Código de Comercio) denominado "subasta pública". Al ofrecer el martillero los bienes a rematar, desde el momento que cualquiera de los presentes ofrece un precio por ellos, nace el acuerdo sobre la cosa, y al culminar la subasta pública, se produce el acuerdo sobre la persona del comprador y el precio. En consecuencia, desde que las partes han convenido en la cosa y en el precio, la compraventa se reputa perfecta (Art. 1.801 del Código Civil) y, conforme a la norma general del artículo 1.545 del Código Civil: "Todo contrato legalmente celebrado es una ley para los contratantes, y no puede ser invalidado sino por su consentimiento mutuo o por causas legales".

Por pretender ser éste un breve ensayo sobre la materia, no se puede exponer en forma exhaustiva toda posible causa legal de invalidación de esta compraventa en remate, pero intentaremos una enunciación genérica de ellas.

En primer lugar, las partes, comprador y vendedor, tendrán las acciones provenientes de los vicios del consentimiento que pudieren afectarles: error, fuerza o dolo, tanto en la celebración del contrato de compraventa, como en la tradición del bien objeto de la compraventa. $Y$ a este respecto recordemos que el inciso tercero del artículo 671 del Código Civil aclara que "en las ventas forzadas que se hacen por decreto judicial a petición de un acreedor, en pública subasta, la persona cuyo dominio se transfiere es el tradente, y el juez su representante legal".

En otro aspecto, podría intentarse la declaración de nulidad del remate por haberse omitido el cumplimiento de los requisitos que la ley prescribe para el valor del acto o contrato en consideración a la naturaleza de ellos. Es interesante al respecto transcribir el artículo 13 de la ley 18.118, que dice: "La venta en martillo no podrá suspenderse por ningún reclamo o cuestión que se suscite durante el remate (debiera decir durante la "subasta" ) y las especies se adjudicarán definitivamente al mejor postor, cualquiera sea el precio ofrecido. Sin embargo, el martillero no adjudicará la respectiva especie si habiendo anunciado un mínimo para las posturas, no hubiere licitadores para ese monto". (Para el cumplimiento de lo anterior, el artículo 14 dispone que "el martillero, bajo su responsabilidad, podrá solicitar el auxilio de la fuerza pública para hacer salir del lugar del remate a cualquiera persona que altere el orden o entor- 
pezca la realización de la subasta"). Confirmando lo anterior, el artículo $9^{\circ}$ del Reglamento declara: "Las ventas en martillo podrán suspenderse antes de que se inicie el pregón del lote, pero una vez formulada la primera oferta se proseguirá hasta la adjudicación definitiva al mejor postor, cualquiera sea el precio ofrecido. Sin embargo, el martillero no adjudicará la respectiva especie si, habiendo anunciado un mínimo para las posturas, no hubiere licitadores para ese monto". Esta excepción es de gran aplicación en las ejecuciones en materia laboral, dado lo dispuesto en la letra c) del artículo 460 del Código del Trabajo.

Las otras normas que regulan esta especial compraventa están establecidas en el Reglamento, de las cuales enunciaremos las más importantes: "El remate con el señalamiento del lugar, dia y hora en que debe verificarse, se anunciará por medio de avisos publicados en uno de los dos periódicos de mayor circulación de la región en que éste se realice. El último aviso deberá ser publicado el día anterior al de la subasta..." : "...se dejará constancia del nombre del martillero, número de su inscripción en el Registro Nacional de Martilleros, lugar en que se encuentran las especies a subastar, días y horas en que pueden inspeccionarse y el valor de la comisión que deberá pagar el comprador si asi correspondiere. ( $A$ este respecto debe recordarse que en los remates judiciales, todo el dinero que obtenga por la venta "será puesto por. el martillero a disposición del tribunal respectivo dentro de los cinco días hábiles siguientes al día del remate", y "...deducirá de dichos dineros los gastos de avisos u otros que demande la subasta y su comisión, la que no podrá exceder del $1 \%$ del producto del remate" ). "Todos los objetos que deban rematarse, organizados por lotes y cada uno de éstos con su respectivo número correlativo, se pondrán a la vista del público el día anterior al de la fecha de la subasta...".

Las normas reglamentarias precedentes regulan requisitos previos a la subasta pública y el remate mismo, pero también, además de la prohibición de suspensión, existen otras exigencias reglamentarias relativas a todo el procedimiento de la subasta, a saber: "El martillero, al pregonar cada lote, expresará su número, procederá a describir su contenido y se abstendrá de hacer recomendaciones que alteren la esencia de la especie que subasta, limitándose a pedir y repetir la oferta con claridad necesaria para ser oído y comprendido por todos los concurrentes". "El postor no proferirá más palabras que las estrictamente necesarias para expresar su oferta". "Si el postor infringiere esta obligación, el martillero podrá desatender su oferta y, además, hacerle salir del lugar del remate". "El martillero podrá exigir al licitador, para admitir sus posturas, o que las afiance o que pague en el acto de adjudicársele la especie". "Si hubiere duda acerca de la persona del adjudicatario o de la conclusión del remate, el martillero reabrirá la licitación sin ulterior reclamo por parte de los anteriores postores". "El adjudicatario recibirá en el acto del remate, una boleta que exprese su nombre y el precio, número y contenido del lote. La entrega de la especie se verificará en vista y de conformidad con este documento".

Por otra parte. tratándose de una compraventa, al vendedor le corresponderá el saneamiento de evicción y de los vicios de redhibitorios. En el tema en estudio no cabría 
la lesión enorme por expresa disposición del artículo 126 del Código de Comercio: "No hay rescisión por causa de lesión enorme en los contratos mercantiles", y especialmente del artículo 1.891 del Código Civil: "No habrá lugar a la acción rescisoria por lesión enorme en las ventas de bienes muebles, ni en las que se hubieren hecho por el ministerio de la justicia". Pero tampoco es cabal el saneamiento de evicción en estos casos, pues el artículo 1.851 del Código Civil dispone que: "En las ventas forzadas hechas por autoridad de la justicia, el vendedor no es obligado, por causa de la evicción que sufriere la cosa vendida, sino a restituir el precio que haya producido la venta". Algo similar ocurre con los vicios redhibitorios, según el artículo 1.865 del mismo Código: "La acción redhibitoria no tiene lugar en las ventas forzadas hechas por autoridad de la justicia. Pero si el vendedor, no pudiendo o no debiendo ignorar los vicios de la cosa vendida, no los hubiere declarado a petición del comprador, habrá lugar a la acción redhibitoria y a la indemnización de perjuicios".

Otro tema relacionado con el remate judicial es el ejercicio de los derechos reales sobre la cosa vendida. Uno de posible ocurrencia frecuente sería el caso en que el deudor ejecutado no fuera dueño de la especie rematada y el verdadero dueño quisiere ejercer la acción reivindicatoria. Esto puede suceder por varias razones, por ejemplo: el verdadero dueño no se enteró oportunamente del embargo y remate; o, concurriendo como tercerista, no pudo fundar su tercería en instrumento público anterior ni en antecedentes que constituyeran presunción grave de la posesión invocada, por lo que no obtuvo la suspención del procedimiento de apremio; o, habiendo obtenido la suspensión, ello no se comunicó válida y oportunamente al martillero, antes de iniciarse el pregón del lote y formulada la primera oferta, o por cualquier otro motivo que hubiera significado el remate de bienes de su dominio. La misma acción reivindicatoria podrá ejercerse respecto de otros derechos reales diferentes del dominio, siendo el más común el derecho real de prenda que tiene el acreedor sobre la especie pignorada, la que puede perseguir en manos de cualquiera que la tuviere en su poder.

Pero frente a estos derechos reales reivindicables se oponen algunas disposiciones legales. Por ejemplo, los incisos segundo y tercero del artículo 890 del Código Civil, donde, después de permitir la reivindicación de todas las cosas corporales, raíces y muebles, se aclara: "Exceptúanse las cosas muebles cuyo poseedor las haya comprado en una feria, tienda, almacén u otro establecimiento industrial en que se vendan cosas muebles de la misma clase", agregando que "justificada esta circunstancia, no estará el poseedor obligado a restituir la cosa, si no se le reembolsa lo que haya dado por ella y lo que haya gastado en repararla y mejorarla". Una disposición similar, relativa sólo al derecho real de prenda, está contenida en el artículo 18 de la Ley 4.702, sobre compraventa de cosas muebles a plazo, que dice: "El derecho de prenda no producirá efecto alguno contra el tercero que haya adquirido la cosa en una fábrica, feria, tienda, almacén u otro establecimiento análogo en que se vendan cosas muebles de la misma clase". Creo que entre los otros establecimientos en que se venden cosas muebles de la misma clase deben considerarse las casas de martillo. Asimismo, aunque en este caso con mención expresa, el artículo 10 de la Ley 18.112, sobre prenda sin desplazamiento. dispone: "El derecho de prenda no será oponible contra el tercero que adquiera la cosa 
empeñada en una fábrica, feria, casa de martillo, tienda, almacén u otros establecimientos análogos en que se vendan cosas muebles de la misma clase".

Por último, no puedo dejar de mencionar las acciones provenientes de los derechos personales que nacen reciprocamente entre comprador y vendedor, como efectos del contrato de compraventa en remate, especialmente las de cumplimiento o resolución del contrato, con indemnización de perjuicios, donde cabe destacar lo dispuesto en el inciso primero del artículo 15 de la ley 18.118 , repetido por el artículo $13^{\circ}$ de su $R e-$ glamento, a saber: "Si transcurridos dos días hábiles de verificado el remate, el adjudicatario no pagare el total del precio de la especie o la cuota al contado, si ésta se hubiere convenido, la adjudicación quedará sin efecto por este solo hecho y se abrirá de nuevo la licitación". O sea, estaríamos frente a un pacto comisorio calificado impuesto por la ley sólo respecto de la obligación del comprador de pagar el precio, pero que, además, produce sus efectos por el solo ministerio de la ley. sin permitirle al vendedor la alternativa de exigir el cumplimiento.

En fin, se han esbozado varias de las acciones que pudieran derivar de la compraventa en remate, aplicables aunque dicho remate se produjere por decreto judicial. Estas acciones deben ejercerse independientemente del juicio en que se decretó el remate, pues ni el martillero ni el comprador son partes en dicho proceso, además que el remate suele ser normalmente posterior a la dictación de la sentencia de término.

En general, estas acciones estarían sometidas al procedimiento del juicio ordinario, pero las que provinieren de infracciones a la ley sobre el ejercicio de la actividad de martillero público y su reglamento se rigen por lo dispuesto en el artículo 24 de la ley 18.118, que dice: "Será competente para conocer de las cuestiones a que diere lugar la infracción a la presente ley y su reglamento, el Juez de Letras en lo Civil correspondiente al domicilio del martillero o del lugar donde se efectuó o debió efectuarse el remate", y agrega en su inciso segundo: "La causa se tramitará en juicio sumario y podrá ser parte en ella toda persona afectada por la infracción o infracciones señaladas". También la acción reivindicatoria del acreedor prendario puede ejercerse mediante el procedimiento sumario, sea por disposición expresa de la ley, como en los artículos 25 de la ley 4.097 ó 38 de la ley 4.702 , sea porque realmente la acción requiere, por su naturaleza, tramitación rápida para que sea eficaz. En el caso de la prenda sin desplazamiento de la ley 18.112, además del derecho a realización inmediata o el desposeimiento de la cosa pignorada en poder del tercero, también se contempla el procedimiento de las querellas posesorias para recuperarlo.

Todo lo expuesto en este acápite es relativo a las acciones, y algunas excepciones, que emanan del contrato de compraventa en remate. Veamos ahora:

\section{ACCIONES O RECURSOS VINCULADOS A LA COMISIÓN PARA VENDER EN REMATE JUDICIAL}

Tal como se ha dejado establecido anteriormente, el martillero actúa en la subasta pública y remate en representación del vendedor, proviniendo dicha representati- 
vidad de un contrato de comisión para vender. La comisión es un mandato especial mercantil y, como tal, el encargo "puede hacerse por escritura pública o privada, por cartas, verbalmente o de cualquier otro modo inteligible, y aun por la aquiescencia tácita de una persona a la gestión de sus negocios por otra...". (Art. 2.123 del Código Civil). También vimos que en las ventas forzadas que se hacen por decreto judicial a petición de un acreedor, en pública subasta, el juez es el representante legal del vendedor.

Ahora bien, dada la trascendencia de esta comisión para vender, el legislador ha reglamentado acuciosamente el perfeccionamiento de este contrato respecto de los remates judiciales. Así, la frase final del artículo 482 del Código de Procedimiento Civil dispone que "la venta se hará por el martillero designado por el tribunal que corresponda". Y esto está reglamentado en el Título IV de la ley 18.118, especialmente sus artículos 19 y 20, que disponen: "Los remates judiciales de especies muebles serán realizados por el martillero que designe el juez de la causa". "La designación deberá recaer en alguno de los martilleros que se hayan inscrito en el registro especial a que se refiere el artículo 20, respetando estrictamente el orden de antigüedad de la inscripción". (Y el artículo 20 dice: "Para los efectos de lo establecido en el artículo anterior, las Cortes de Apelaciones mantendrán un registro especial en el cual deberán inscribirse los martilleros interesados en realizar subastas judiciales". "El martillero deberá tener una antigüedad de, a lo menos, dos años en el ejercicio de su actividad, para optar a la inscripción"). "Si no hubiere interesados, podrá nombrar a cualquiera de los que figuren en la lista a que se refiere la letra e) del artículo 10". ("Corresponderá a la Subsecretaría de Economía Fomento y Reconstrucción: ...e) Enviar a las Cortes de Apelaciones, en el mes de Diciembre de cada año, las nóminas de martilleros inscritos a dicha fecha, que tengan su domicilio en la respectiva jurisdicción"). "En todo caso, el juez de la causa no podrá nominar dos veces consecutivas a la misma persona cuando hubiere dos o más martilleros en su jurisdicción". "El martillero, una vez designado, no podrá eximirse de practicar remates judiciales sin causa justificada".

Los artículos 21 y 22 reglamentan, atendida la especial naturaleza del remate judicial, las mismas obligaciones y derechos del comisionista que regulan los artículos 275, 278 y 279 del Código de Comercio, relativos a la rendición de cuenta, gastos y comisiones.

Sin embargo, debe considerarse que la representatividad que el juez detenta para encargar la venta al martillero proviene de la ley, en virtud de conocer y fallar un debido proceso judicial. De modo que a este contrato de comisión para vender, además de todos los vicios, acciones y excepciones propios del contrato, pueden afectar a su validez los vicios procesales del juicio en que se decreta el remate.

Debo insistir que, en mi opinión, los vicios procesales solamente afectarían al vinculo jurídico entre el comisionista martillero y el comitente vendedor, representado legalmente por el juez. Pero en ningún caso los vicios procesales podrían afectar a la validez del remate. La compraventa celebrada entre el martillero y el comprador, mejor postor, sólo podría impugnarse por vicios propios de dicho contrato de compraventa 
especial. En otras palabras, los vicios procesales son inoponibles al comprador y al martillero en su calidad de vendedor, puesto que ninguno es, ha sido, ni puede ser, parte en el juicio.

En todo caso, debe quedar claro que lo anteriormente afirmado es sobre la base que el remate se llevó a efecto legalmente. $Y$ es por ello que el artículo 22 de la ley 18.118 reconoce expresamente al juez de la causa la facultad de suspender el remate "por resolución judicial". Pero la misma norma dispone que "las especies embargadas en juicio, cuya subasta haya sido suspendida por resolución judicial y que permanezcan en poder del martillero por más de tres meses contados desde la fecha de la suspensión, podrán ser rematadas por éste sin más requisito que la publicación de los avisos que procedan legalmente, salvo resolución en contrario dictada por el juez de la causa".

Pongamos un ejemplo: Ante la interposición de una tercería de dominio fundada en instrumento público anterior a la demanda, el juez ordena la suspensión del remate. Pasan más de tres meses desde la notificación al martillero de la resolución judicial de suspensión, por lo que, previas las publicaciones de los avisos exigidos por la ley. el martillero remata los bienes. No hay resolución en contrario dictada por el juez, porque los interesados no se lo hacen presente. ¿Qué sucedería si posteriormente se dicta en el proceso sentencia de término acogiendo la tercería y alzando el embargo? ¿Sería válido el remate? ¿En qué situación quedaría el tercerista? ¿Y si en vez de tercería fuera una nulidad procesal lo que se declara?.

En mi opinión, el remate sería plenamente válido. Al comprador le sería inoponible la sentencia que declaró el dominio del tercerista o la nulidad procesal, por no ser parte en el juicio. El tercerista podría intentar una acción reivindicatoria u otra en contra del comprador, con las dificultades que ya vimos para que prosperara dicha acción. En todo caso el tercerista, haya habido o no suspensión, estimo que podría, para sustentar su pretensión, esgrimir lo dispuesto en el inciso segundo del artículo 523 del Código de Procedimiento Civil: "...el remate se llevará a cabo, entendiéndose que la subasta recaerá sobre los derechos que el deudor tenga o pretenda tener sobre la cosa embargada". En cambio el martillero, comisionista para vender, que "deberá sujetarse estrictamente en el desempeño de la comisión a las órdenes o instrucciones que hubiere recibido de su comitente"; que "en ningún caso podrá obrar contra las disposiciones expresas y claras de su comitente", y que "en todos los casos no previstos por el comitente, el comisionista deberá consultarle y suspender la ejecución de su encargo mientras reciba nuevas instrucciones". (Arts. 268 y 269 del Código de Comercio), entiendo que, a pesar del texto del artículo 22 de la ley 18.118, debió informar y consultar al juez de la causa, su comitente, y al no hacerlo así deberá responder de los perjuicios causados.

\section{COROLARIO}

La venta en martillo o remate, en estudio, es un contrato de compraventa de cosas corporales muebles, en la que el vendedor está representado por el martillero públi- 
co, el precio se determina mediante subasta pública y el comprador es el mejor postor. Por consiguiente, los efectos del contrato, derechos y obligaciones de las partes, no difieren de otros contratos de compraventa, salvo en lo referente al cumplimiento u omisión de los requisitos especiales señalados por la ley sobre la forma de efectuar la subasta, que podrían afectar a su validez.

Lo anterior es aplicable también a los llamados remates judiciales, cuya única diferencia estriba en que el vendedor encarga la venta al martillero público representado legalmente por el juez de la causa, pero en nada podrá afectar al contrato de compraventa cualquier incidente o resolución que se dicte en el proceso, si no le es notificada legalmente al martillero antes de iniciado el pregón y formulada la primera oferta.

Ahora bien, la representatividad del martillero nace de un contrato de comisión para vender, que celebra con el vendedor $o$, en el caso de los remates judiciales, con el juez de la causa en su calidad de representante legal del vendedor. Los derechos y obligaciones del martillero comisionista están más estrictamente reglamentados en los remates judiciales, en lo referente al monto de la comisión que puede percibir, los gastos que puede descontar, el plazo para la rendición de cuenta y consignación del producto del remate y los efectos de las suspensiones que podría decretar su comitente juez de la causa. $Y$ es a este contrato de comisión para vender al que podrían afectarle las incidencias, nulidades $u$ otras resoluciones judiciales dictadas en el juicio en que se decretó el remate.

En consecuencia, una vez efectuado el remate, las partes del juicio, entre las que se contaría a los terceristas, sólo podrían impugnar en el proceso el contrato de comisión para vender en virtud del cual el martillero remató las especies, pero nada de ello serviría para invalidar la compraventa ya efectuada. Del mismo modo, ni el comprador (mejor postor)- ni el martillero, podrían impugnar ningún trámite procesal, por no ser partes en el juicio, y solamente tendrían las acciones correspondientes al contrato de compraventa que celebraron.

El vendedor, deudor del juicio en que se decretó el remate, si obtiene una nulidad procesal podría demandar al comprador y al martillero alegando la inoponibilidad de la comisión para vender, toda vez que dicha nulidad podría afectar a la representatividad legal del juez. Y el tercerista de dominio, o de posesión que hace presumir el dominio, si obtiene en su tercería, podrá entablar la acción real que estime conveniente en contra del comprador, al igual que quien tuviere un derecho real de prenda, usufructo u otro, con las dificultades para obtener éxito que ya se insinuaron en este trabajo. 